\title{
In Vitro Comparison of Antibacterial Effects of Ziziphora clinopodioides L. and Some Standard Antibiotics on Bacteria Isolated From Women's Urogenital Tract Infections
}

\author{
Younes Anzabi*
}

\begin{abstract}
Objectives: Medicinal aromatic herbs have been used traditionally as a strong source of natural drugs for many centuries. This work aimed to compare the antibacterial activity of Ziziphora clinopodioides' essential oils and four standard antibiotics against some pathogenic bacteria isolated from women's urogenital tract infections in order to replace natural antibacterial compounds from plant instead of synthetic chemical antibiotics.

Materials and Methods: To evaluate the antibacterial effects of essential oils of mentioned plant and standard antibiotics including nalidixic acid, vancomycin, ceftizoxime and tetracycline according to the guideline of the standard disk diffusion method test constituted by the CLSI (formerly NCCLS) and executed on each isolate using Mueller-Hinton agar medium.

Results: The results indicated that the essential oils of Ziziphora clinopodioides L. exhibited resistance to moderate and sensitive antibacterial activity on the tested bacteria with inhibition zone (IZ) value ranging from $5 \pm 0.1 \mathrm{~mm}$ to $29.1 \pm \pm 0.2 \mathrm{~mm}$. Also at $5 \%$ level of confidence; there was no significant difference between antibacterial effect of essential oils of mentioned plants and the tested standard antibiotics.

Conclusion: The present study showed that the Ziziphora clinopodioides L. essential oils' was effective on many tested bacteria as compared to the standard antibiotics and like other species of Ziziphora has a great potency of being used as natural antimicrobial drug; therefore it can be used against bacteria causing urogenital tract infections in women. It is suggested that in this connection supplementary study should be done on experimental animal models.

Keywords: Essential oils, Infection, Medicinal, Plants, Urogenital system, Women
\end{abstract}

\section{Introduction}

Medicinal aromatic herbs have been used traditionally as a strong source of vegetables, spices and natural drugs for many centuries. Thus many recent researchers have become interested in its chemical extraction and antimicroorganism properties $(1,2)$.

The Ziziphora genus belongs to Lamiaceae family, with more than 15 species, mainly distributed in the Mediterranean mountainous regions of Europe, Asia and Africa. This plant with the Persian name of Kakuti, consists of four species including Ziziphora clinopodioides, Ziziphora tenuior, Ziziphora capita and Ziziphora persica is found in mountainous regions of Iran (3-5).

Many researches have been conducted on the antioxidant, antibacterial and antifungal activities of the plants. It has been shown in Iranian and many Asian traditional medicine, such as Turkey, that the infusions of Ziziphora species, especially Ziziphora clinopodioides, have been used as antiseptic, carminative and sedative agent to treat cold, flu, cough, stomach ache and diarrhea $(1,6-10)$.

In relation to the phytochemical properties of Zizipho- ra genus, many researchers suggested that the Ziziphora species are rich in monoterpenoides and phenolic compounds such as thymol, pulegone, piperitenone and p-menth-3-en-8-ol, which can have antioxidant and antimicrobial activity against many infectious diseases and pathogens $(2,11,12)$.

Due to the extensive distribution of Ziziphora clinopodioides L. and also the wide usage of it in traditional medicine of different regions of East Azerbaijan in Iran, this work was performed to determine the antibacterial activity of Ziziphora clinopodioides L. essential oils and some standard antibiotics against the pathogenic and opportunistic pathogens isolated from women with urogenital tract infections, in order to replace natural antibacterial compounds from that plant rather than synthetic chemical antibiotics from this region.

\section{Materials and Methods}

Collecting Plants Material

The aerial parts of Ziziphora clinopodioides in blooming were collected from the wild region hills $15-20 \mathrm{~km}$ far 
from Tabriz (1700-1800 m) in East Azerbaijan province. A voucher specimen of plants was identified and preserved at the Herbarium of Food Hygiene Department of Tabriz branch, Islamic Azad University,Tabriz, Iran. Then the plant samples were dehydrated in the shadow, powdered and stored at $4^{\circ} \mathrm{C}$ until tested in vitro $(6,13)$.

Preparation of the Plants' Essential Oils

In the specialized laboratory in the Department of Pathobiology, Tabriz branch, Islamic Azad University, water distillation method and Clevenger apparatus was used for production of Ziziphora clinopodioides' essential oils $(1,14)$.

\section{Bacterial Strains}

The examined bacteria in this study included 9 species of isolated bacteria from urogenital tract infections (UTIs) of female patients that had referred to the Microbiology Laboratory of Tabriz Red Crescent in 2014. The micro-organisms included Staphylococcus aureus, Staphylococcus epidermidis, Staphylococcus saprophyticus (gram positive isolated bacteria) and Escherichia coli, Klebsiella pneumonia, Citrobacter frundii, Proteus vulgaris, Enterobacter aerogenes and Pseudomonas aeruginosa (gram negative isolated bacteria).

Preparation of Bacterial Suspension

Considering the fact that preparation of a microbial suspension requires a new culture for every bacterium, therefore about 24 hours before each experiment, a suspension of each organism was equipped from fresh colonies on BHI agar medium (Merck, Germany) at 18-24 hours incubation in $37^{\circ} \mathrm{C}$. Then purified colonies of each isolate were created in a medium washed with normal saline and the turbidity of bacterial suspension was set to tube of No. 0.5 of McFarland standard. Microbial suspension of all isolates used in various experiments in this study contained $\sim 1.5 \times 10^{8} \mathrm{CFU} / \mathrm{ml}$ of the tested isolated bacteria $(15,16)$.

Preparation of Antibacterial Disks for Antibiogram Test The disks containing essential oils of mentioned plants were prepared from sterile blank disks manufactured in Padtan-Teb Company (Tehran, Iran). Thus the blank disks were placed in tubes containing essential oils of Ziziphora clinopodioides for 30 to 50 minutes following the complete absorption by disk. Then the disks were placed at $44-45^{\circ} \mathrm{C}$ until completely dry and ready for the experiment. The standard antibiotic disks (Nalidixic acid, vancomycin, ceftizoxime and tetracycline) were prepared according to the producer's instruction; Padtan-Teb Company (Tehran, Iran) (17).

Antibiogram Test With Ziziphora clinopodioides Essential Oils' and Four Standard Antibiotics

For this purpose, according to the guideline of the standard disk diffusion method test constituted by the CLSI (formerly NCCLS), the disk diffusion method test was executed separately on each isolate using Mueller-Hinton agar medium. (Merck, Germany) (18). The entire surface of the medium plate (diameter: $90 \mathrm{~mm}$ ) was covered with the required inoculums of each bacterial suspension separately and the antibiotic disks were laid on the surface of the medium and incubation was performed for 18-24 hours at $37^{\circ} \mathrm{C}$. The results were recorded by measuring the diameter of inhibition zone (IZ) around the mentioned disks. To make sure, this work was repeated three times for each isolated bacteria. The mean of inhibition zone diameter in the final three repeats was registered as the final inhibition zone diameter $(16,19,20)$.

Statistical Analysis

In order to find the relationship between sensitive and resistant strains despite the type of isolated bacteria chiSquare and independent $t$ test were used. Also data in the range of $P<0.05$ were considered statistically significant (subset for alpha $=0.05$ ).

\section{Results}

IZ of the essential oils of Ziziphora clinopodioides L. as compared to standard antibiotics (nalidixic acid, vancomycin, ceftizoxime and tetracycline) are shown in Table 1. The results indicated that the essential oils of Ziziphora clinopodioides L. exhibited most and least antibacterial activity on tested bacteria with IZ value ranging from $5 \pm 0.1 \mathrm{~mm}$ (for Pseudomonas aeruginosa) to $29.1 \pm 0.2$ $\mathrm{mm}$ (against Klebsiella pneumonia), respectively. Also in $5 \%$ level of confidence there was no significant difference between antibacterial effect of essential oils of the mentioned plants and tested standard antibiotics on most of isolates. Indeed compared with standard antibiotics, in most of the cases (except Pseudomonas aeruginosa), the essential oils showed higher antibacterial activity. The results of this work showed that by comparison of the antibacterial effects of the Ziziphora clinopodioides' essential oils with the tested standard antibiotics effects, it can be concluded that the essential oils from this plant were able to prevent the growth of the studied bacteria.

\section{Discussion}

Ziziphora clinopodioides L. belongs to Lamiaceae family, which is widely is the most wild aromatic annual herb, which often grow in north slob and sunny position around of hills on the city of Tabriz in East Azerbaijan province (at the height of 1700-1800 m), with dry cold climate in the sandy loam soil, and $\mathrm{pH}=7.8$. Also ethnopharmacological data about this plant showed that it has been used by the rural people as an antispasmodic, anti-inflammatory, anti fungal, expectorant and sedative agent to treat cold, flu, diarrhea, gasterointestinal disorder and stomach ache $(1,7,8)$.

On the other hand, the increasing resistance to antimicrobial factors justifies the necessity of finding new natural drugs with antibacterial effects from different natural plants. The Ziziphora clinopodioides L. contains many phytochemical substances including terpenoids and phenolics which have an antibacterial, antioxidant, antifungal 
Table 1. Mean of Inhibition Zone $(\mathrm{mm}) \pm \mathrm{SD}$ of Tested Antibacterial Compounds (Essential Oils of Ziziphora clinopodioides and Four Standard Antibiotics) ${ }^{\mathrm{a}}$

\begin{tabular}{|c|c|c|c|c|c|}
\hline Name of Isolated Bacteria & $\begin{array}{l}\text { Ziziphora clinopodioides } \\
\text { Essential Oils ( } 30 \mu \mathrm{L} / \mathrm{disk})\end{array}$ & $\begin{array}{r}\text { Nalidixic Acid } \\
(30 \mu \mathrm{g} / \text { disk })\end{array}$ & $\begin{array}{l}\text { Vancomycin } \\
\text { (30 } \mu \mathrm{g} / \text { disk) }\end{array}$ & $\begin{array}{l}\text { Ceftizoxime } \\
\text { (30 } \mu \mathrm{g} / \text { disk) }\end{array}$ & $\begin{array}{l}\text { Tetracycline } \\
\text { (30 } \mu \mathrm{g} / \text { disk) }\end{array}$ \\
\hline Staphylococcus aureus & $22 \pm 0.2$ & $13 \pm 0.1$ & $19 \pm 0.1$ & $20 \pm 0.2$ & $15 \pm 0.1$ \\
\hline Staphylococcus epidermidis & $20 \pm 0.2$ & $14 \pm 0.1$ & $17 \pm 0.1$ & $18 \pm 0.1$ & $17 \pm 0.1$ \\
\hline Staphylococcus saprophyticus & $21 \pm 0.2$ & $14 \pm 0.1$ & $15 \pm 0.1$ & $19 \pm 0.1$ & $14 \pm 0.1$ \\
\hline Escherichia coli & $21 \pm 0.2$ & $13 \pm 0.1$ & $11 \pm 0.1$ & $17 \pm 0.1$ & $9 \pm 0.1$ \\
\hline Klebsiella pneumonia & $29 \pm 0.2$ & $19 \pm 0.1$ & $18 \pm 0.1$ & $18 \pm 0.1$ & $11 \pm 0.1$ \\
\hline Proteus vulgaris & $19 \pm 0.1$ & $9 \pm 0.1$ & $12 \pm 0.1$ & $15 \pm 0.1$ & $14 \pm 0.1$ \\
\hline Enterobacter aerogenes & $19 \pm 0.1$ & $11 \pm 0.1$ & $14 \pm 0.1$ & $19 \pm 0.1$ & $13 \pm 0.1$ \\
\hline Citrobacter frundii & $20 \pm 0.2$ & $4 \pm 0.1$ & $16 \pm 0.1$ & $19 \pm 0.1$ & $15 \pm 0.1$ \\
\hline Pseudomonas aeruginosa & $5 \pm 0.1$ & 0 & 0 & 0 & 0 \\
\hline
\end{tabular}

a Significant difference: $P<0.05$, Subset for alpha $=0.05$.

and anti-inflammatory effect $(10,21)$.

Analysis of results in this work (Table 1) also revealed that almost all of tested bacteria are absolutely sensitive to essential oils of Ziziphora clinopodioides and showed more antibacterial activity than the standard antibiotics (nalidixic acid, vancomycin, ceftizoxime and tetracycline).

In confirming the results of this paper; Soltani et al in 2013 showed that the Ziziphora clinopodioides extract had a significant antibacterial potential on some bacteria and it may be effective in the treatment of infectious disease caused by Listeria, Shigella and Escherichia genuses (the most common cause of bacterial dysentery) (10,21-23). The results of this work showed that the essential oils of Ziziphora clinopodioides had inhibitory effect on the isolated gram positive and gram negative bacteria from woman's urogenital tract infections. Moreover this combination had more antibacterial effect on the gram-negative isolates (except for Pseudomonas aeruginosa isolates). In this connection, majority of researches suggested that the sensitivity of gram-negative bacteria against antimicrobial compounds in comparison to gram-positive bacteria is lesser, and this seem to be due to the type of composition present in the cell wall of the bacteria. Also studies indicated that antibiotic resistance of different serotypes of Pseudomonas aeruginosa is related to antibiotic use and may be intrinsic (genetic origin) or acquired by plasmid. It has been shown that various serotypes of Pseudomonas aeruginosa create multidrug resistance (MDR) through various mechanisms especially biofilm formation and efflux pump. This explains why MDR strains of this bacterium are increasing worldwide which would be consistent with the findings of present study. According to the results recorded in Table 1, none of the isolates of Pseudomonas aeruginosa showed microbial sensitivity to any of the tested standard antibiotics and even essential oils of Ziziphora clinopodioides (17).

Finally in reports on Ziziphora species and also many similar researches about the medicinal effects of many species of Lamiaceae family such as Ziziphora clinopodioides it has been shown that properties of this plants are associated with their phenolic substances, which can be dependent on the many factors such as geographic situation, weather conditions, season, kind of soil and drying and extracts methods (2,24-26).

\section{Conclusion}

The present study showed that the essential oils of Ziziphora clinopodioides $\mathrm{L}$. were more effective on many tested bacteria than the standard antibiotics (nalidixic acid, vancomycin, ceftizoxime and tetracycline). This work is the first research for identification of antibacterial activities of Ziziphora clinopodioides essential oils' on the pathogenic or opportunistic pathogens isolated from women's urogenital tract infections in East Azerbaijan province.

Also our results confirmed the traditional use of this plant as an anti-spasmodic, anti- inflammatory, anti-infective and sedative agent in treating diarrhea, gastrointestinal disorders and stomach ache. Therefore, it seems that Ziziphora clinopodioides L. essential oils have a great potency of antimicrobial properties and we can use different plant combinations for the production of natural antimicrobial compounds in the pharmaceutical industry. It is suggested that in this connection supplementary study should be done on experimental animals' models.

\section{Ethical issues}

This study has been carried out with taking informed consent from patients for using samples.

\section{Financial support}

All expenses related to this research are provided by the author.

\section{Conflict of interests}

The author declares no conflict of interests.

\section{Acknowledgments}

I am grateful to Tabriz branch, Islamic Azad University and Tabriz Red Crescent authorities, especially Miss. H. Taj-Asgari for their useful collaboration.

\section{References}

1. Salehi P, Sonboli A, Eftekhar F, Nejad Ebrahimi S, Yousefzadi M. Essential oil composition, antibacterial and antioxidant activity of oils and various extracts of Ziziphora clinopodioides subsp rigida (Boiss). Biol 
Pharm Bull. 2005;28(10):1892-1896. doi:10.1248/ bpb.28.1892.

2. Aliakbarlu J, Farnaz Shameli F. In vitro antioxidant and antibacterial properties and total phenolic contents of essential oils from Thymus vulgaris, T. kotschyanus, Ziziphora tenuior and Z. clinopodioides. Turk J Bioch. 2013;38(4):425-431. doi:10.5505/tjb.2013.58070.

3. Rechinger KH. Satureja. In: Cavaleiro C, Salgueiro LR, Antunes T, eds. Flora Iranica. Graz, Austria: Sevinate; 1980.

4. Ozturk Y, Aydm S, Tecik B, Baser KH. Effects of essential oils from Ziziphora species on swimming performance in mice. Phytother Res. 1995;9(3):225-227. doi:10.1002/ ptr.2650090315.

5. Mozaffarian VA. Dictionary of Iranian plant names. Tehran, Iran: Farhang Moaser; 1996.

6. Zargari A. Iranian medicinal plants. Tehran, Iran: Tehran University Press; 1995:103-104.

7. Sonboli A, Mirjalili MH, Hadian J, Ebrahimi SN, Yousefzadi M. Antibacterial activity and composition of the essential oil of Ziziphora clinopodioides subsp. bungeana (Juz.) Rech. f. from Iran. Zeitschrift für Naturforschung C. 2006;61(9-10):677-680. doi:10.1515/ znc-2006-9-1011.

8. Behravan J, Ramezani M, Hassanzade MK, Eskandari M, Kasaian J, Sabeti Z. Composition, antimycotic and antibacterial activity of Ziziphora clinopodioides Lam. Essential oil from Iran. J Essent Oil-Bearing Plants. 2007;10(4):339-345. doi:10.1080/097206 0X.2007.10643565.

9. Ozturk S, Ercisli S. Antibacterial activity and chemical constitutions of Ziziphora clinopodioides. Food Control. 2007;18(5):535-540. doi:10.1016/j. foodcont.2006.01.002.

10. Soltani SR, Shapouri R, Mola Abas Zade H, Modirrousta S. Evaluation of antimicrobial effect of hops and Ziziphora clinopodioides extracts on intramacrophages Listeria monocytogenes by agar well diffusion method and cell culture of macrophage. Infect Epidemiol Med. 2013;1(1):27-32.

11. Sajadi SE, Ghasemi Dehkordi NA, Baluchi M. Volatile constituents of Ziziphora clinopodioides Lam. Pajouhesh-Va-Sazandegi. 2003;16(1):97-100. [Persian].

12. Thuille N, Fille M, Nagl M. Bactericidal activity of herbal extracts. Int J Hyg Environ Health. 2003;206(3):217221. doi:10.1078/1438-4639-00217.

13. Pourmorad F, Hosseinimehr SJ, Shahabimajd N. Antioxidant activity, phenol and flavonoid contents of some selected Iranian medicinal plants. Afr J Biotechnol. 2006;5(11):1142-1145.

14. Babayi L, Kolo JI, Ijah UJ. The antimicrobial activities of methanolic extracts of Eucalyptus camaldulensis and Terminalia catappa against some pathogenic microorganisms. Biochemistry. 2004;16(2):106-110.

15. Ip M, Lai Lui S, Poon VK, Lung I, Burd A. Antimicrobial activities of silver dressings: an in vitro comparison. J Med Microbiol. 2006;55:59-63. doi:10.1099/ jmm.0.46124-0.

16. Clinical and Laboratory Standards institute. Performance standards for antimicrobial susceptibility testing twentythird informational supplement, M100-S23. Pennsylvania: CLSI; 2013.

17. Anzabi Y, Khaki A. Antibacterial effects of the essential oils and ethanol extracts of the native plants; Ziziphora clinopodioides on 3 species of urinary tract isolated bacteria in rats' experimental model. Medical J Tabriz Univ Medical Sci Health Services. 2015;37(3):18-25. [Persian].

18. Fiebelkorn KR, Crawford SA, McElmeel ML, Jorgensen JH. Practical disk diffusion method for detection of inducible clindamycin resistance in Staphylococcus aureus and coagulase-negative staphylococci. J Clin Microbiol. 2003;41(10):4740-4744. doi:10.1128/ JCM.41.10.4740-4744.2003.

19. National Committee for Clinical Laboratory Standards. Performance standards for antimicrobial susceptibility testing, 12th informational supplement M100-S12. Wayne, PA: National Committee for Clinical Laboratory Standards; 2002.

20. Centers for Disease Control and Prevention. National antimicrobial resistance monitoring system: enteric bacteria, 2001 annual report. Atlanta, GA: National Antimicrobial Resistance Monitoring System; 2003.

21. Zanoli P, Zavatti M. Pharmacognostic and pharmacological profile of Humulus lupulus L. J Ethnopharmacol. 2008;116(3):383-396. doi:10.1016/j. jep.2008.01.011.

22. Ozturk S, Ercisli S. The chemical composition of essential oil and in vitro antibacterial activities of essential oils and methanol extract of Ziziphora persica bunge. J Ehtanopharmacol. 2006;106(3):327-376. doi:10.1016/j.jep.2006.01.014.

23. Zali MR, Moez Ardalan K, Parcham Azad K, NikKholgh B. Etiologies of acute diarrheal disease in iran. J Res Med Sci. 2003;7(4):346-56. [Persian].

24. Bagamboula CF, Uyttendaele M, Debevere J. Inhibitory effect of thyme and basil essential oils, carvacrol, thymol, estragol, linalool and p-cymene towards Shigella sonnei and S. flexneri. Food Microbiol. 2004;21(1):33-42. doi:10.1016/S0740-0020(03)00046-7.

25. Mazandarani M, Makari S, Bajian GR, Zarghami Moghaddam P, Abrodi M. Evaluation of phytochemical and antioxidant activity in different parts of Heracleum gorganicum Rech. in Golestan province of Iran. Iran J Plant Physiol. 2012;2(2):381-386.

26. Mahboubi A, Kamalinejad M, Ayatollahi AM, Babaeian M. Total phenolic content and antibacterial activity of five plants of Labiatae against four foodborne and some other bacteria. Iran J Pharm Res. 2014;13(2):559-566.

Copyright $(2016$ The Author(s); This is an open-access article distributed under the terms of the Creative Commons Attribution License (http://creativecommons.org/licenses/by/4.0), which permits unrestricted use, distribution, and reproduction in any medium, provided the original work is properly cited. 